\title{
Population characteristics and the distribution of general medical practitioners
}

\author{
M J BUXTON, R E KLEIN
}

is reviewing the criteria for identifying such areas and measures to improve their conditions.

We tried to analyse what the effects of applying to the familypractitioner services the conceptual approach of the RAWP

\section{Summary and conclusions}

By applying the logic of the Resource Allocation Working Party to the analysis of the distribution of general medical practitioners, the relevant Family Practitioner Committee (FPC) populations were weighted according to known patterns of use related to specific characteristics -namely, age, sex, marital state, and socioeconomic group. Comparative weightings were also calculated using standardised mortality ratios. Adjusting the populations to take account of differential use has relatively little impact on national variations in list sizes but an appreciable effect on particular FPCs, notably East and West Sussex, Dorset, and the Isle of Wight. Inequalities in the distribution of general practitioners are increased considerably, however, if figures taking account of the inflation of list sizes and crossboundary flows are used.

To formulate and monitor policy about the distribution of general practitioners more sensitive measures of population and its likely demand for services must be developed.

\section{Introduction}

The debate and controversy about the distribution of National Health Service resources continue. Yet one of the major elements of NHS provision-general medical practitioners-has been effectively excluded from much of the recent discussion. The Report of the Resource Allocation Working Party (RAWP) ${ }^{1}$ recognised that the services provided by family practitioners and health authorities were interrelated and that "geographical disparities" in the distribution of family practitioners should be taken into account. But the family-practitioner services were not included in its formula, and the report made no recommendation on this issue, apart from proposing further studies. Since the establishment of the NHS the Medical Practices Committee has operated a system designed to reduce the geographical disparities in the distribution of general practitioners, and a working party on under-doctored areas

Policy Studies Institute, London SW1E 6DR

M J BUXTON, BA, fellow

University of Bath, School of Humanities and Social Sciences, Bath BA2 7AY

R E KLEIN, MA, professor of social policy formula might be-specifically that of using weighted populations. Published studies of the distribution of family practitioners have used "head counts" to measure the variation of provision." Similarly, unweighted measures of list size are the major factors in deciding the classification of the 1459 English medical practice areas, although special account is taken of other factors -for example, above-average percentages of elderly patients on a doctor's list. ${ }^{3}$ But the logic of RAWP is that the distribution of NHS resources should be related, not simply to patient numbers, but to local populations systematically weighted by relevant population characteristics-that is, those characteristics that determine, or are associated with, variations in demand for service. This paper is a first step towards devising and applying various possible weighting systems for Family Practitioner Committee (FPC) services.

\section{Methods}

Ideally, any analysis of the distribution of health care should be based on population weighted by need. But the concept of need is a peculiarly elusive on $e^{4}$ in health care generally and even more so in the specific case of general practice. The RAWP report used standardised mortality ratios (SMRs) as proxy indicators of need, and has been much criticised for doing so. ${ }^{5}$ But granting that SMRs may be an acceptable, if rough-and-ready, indicator of need for hospital services, they are less obviously applicable to the family practitioner services. In their case, morbidity would seem to be a far more relevant measure of need. Unfortunately, as the RAWP report recognised, statistics of morbidity are both sparse and notoriously difficult to interpret. In any event, they are mostly unavailable in the disaggregated form required for an analysis of general-practitioner distribution by FPC areas.

In our analysis (for which the methodological details are available separately ${ }^{6}$ ) we therefore initially adopted the second-best solution of weighting population by known variations in use of general-practitioner services. Examples of such variations in use are well documentedfor example, studies of particular practices have emphasised the relatively high consulting rate for elderly patients, ${ }^{7}$ and analysis of national data has emphasised the variations between different social classes. ${ }^{8}$ Such patterns of use must not be confused with patterns of need, since the availability of resources and the attitudes of doctors, among other factors, intervene between "need" and observed use. Nevertheless, it seems to be more realistic to analyse the distribution of general practitioners in terms of such weighted populations than in terms of crude list size irrespective of the characteristics of the population concerned.

The data on use of FPC services were calculated from the results of the General Household Survey (GHS), which records, inter alia, the number of consultations with general practitioners made by a sample of the total population. For 1973-6, for which detailed OPCS figures were made available to us, clear indications of temporal trends 
among particular population subgroups were few, although there was an overall fall in general-practitioner consultation rates (from 3.5 per person per year in 1973 to 3.3 in 1976). ${ }^{9}$ The data for the four ycars were therefore combined to increase the size of the sample and hence to improve the reliability of the consultation rates for particular subgroups of the population. Rates of use were then calculated for each group according to age, sex, and marital state and separately for each group according to age, sex, and social group. A six age-band classification was used that distinguished the particularly high rates of use of the very young (under 5s) and the old (over 75s); marital state distinguished between single, married, and the widowed, divorced, or separated; the social-group breakdown used the standard collapsed version of the socioeconomic group (SEG) classification of occupations comprising seven groups. Table I shows the data for males according to age and social group.

TABLE I-Total general-practitioner consultation rates per year for males, according to age and social group. Figures are averages for England and Wales, 1973-6*

\begin{tabular}{cccccccc}
\hline \multirow{2}{*}{ Age } & \multicolumn{7}{c}{ Social group $\dagger$} \\
\cline { 2 - 8 } & 1 & 2 & 3 & 4 & 5 & 6 & Other \\
\hline $0-4$ & $4 \cdot 7$ & $4 \cdot 2$ & $4 \cdot 4$ & $3 \cdot 8$ & $5 \cdot 2$ & $(4 \cdot 2)$ & $(4 \cdot 3)$ \\
$5 \cdot-14$ & $2 \cdot 9$ & $2 \cdot 6$ & $2 \cdot 3$ & $2 \cdot 3$ & $2 \cdot 2$ & $1 \cdot 8$ & $1 \cdot 6$ \\
$15-44$ & $1 \cdot 9$ & $1 \cdot 9$ & $2 \cdot 2$ & $2 \cdot 7$ & $2 \cdot 5$ & $3 \cdot 2$ & $1 \cdot 2$ \\
$45-64$ & $2 \cdot 1$ & $2 \cdot 5$ & $4 \cdot 0$ & $3 \cdot 9$ & $4 \cdot 0$ & $5 \cdot 5$ & $1 \cdot 1$ \\
$65-74$ & $(4 \cdot 3)$ & $4 \cdot 4$ & $4 \cdot 0$ & $4 \cdot 0$ & $4 \cdot 0$ & $3 \cdot 7$ & $(1 \cdot 3)$ \\
$\geqslant 75$ & $(5 \cdot 0)$ & $7 \cdot 0$ & $5 \cdot 8$ & $5 \cdot 4$ & $5 \cdot 6$ & $(6 \cdot 0)$ & $(2 \cdot 2)$ \\
\hline
\end{tabular}

*Derived from General Household Survey, unpublished tabulations.

Social groups-Standard collapsed version of SEG classification of occupations (1) professional (SEG 3, 4); (2) employers and managers (SEG 1, 2, 13); (3) inter mediate and junior non-manual (SEG 5, 6); (4) skilled manual (including foreme and supervisors) and own-account non-professionals (SEG 8, 9, 12, 14); (5) semi-
skilled manual and personal service (SEG 7, 10, 15); (6) unskilled manual (SEG 11) other, all other

Note-Figures in brackets derived from sample cell of less than 200 persons.

Despite the smaller sample, the GHS data were used in preference to those of the Second National Morbidity Survey ${ }^{10}$ because the latter does not give a breakdown according to social class or marital state, although both factors are associated with major variations in use-for example, among men aged 45-64 those in the "professional" socioeconomic groups have an average consultation rate of $2 \cdot 1$ (per person per year) compared with 5.5 for the "unskilled"; among women aged 15-44 the consultation rate for single women was $3 \cdot 2$ compared with 4.7 for married women. The GHS data also record the location of consultation and permit an allowance for the greater work load imposed by home visits to be calculated. This is likely to be important, since the proportion of total consultations made in the home varies with both age and social class.

These detailed national consultation rates were then applied to individual FPC population figures (from the 1971 Census) broken down by age, sex, and marital state and by social groups, and alternative series of weights calculated that measured the extent to which the characteristics of the local populations might generate more or fewer general-practitioner consultations than the national average. For those weights that distinguished between home visits and other consultations, home visits were counted as equivalent to two surgery consultations on the basis of studies of the relative times concerned. ${ }^{11}$

\section{Effects on particular FPCs of using population weightings}

Table II shows those FPCs for which at least one of the population weights would affect the population measure by at least $2.5 \%$. Surprisingly perhaps, only 20 authorities would be so affected. Several explanations for this finding are possible. Firstly there are self-cancelling patterns in the age composition of the local populations : FPCs with a large concentration of the elderly tend to have a low proportion of young children, and these are the two population groups which make the highest demands on general-practitioner services. Secondly, social-class variations in consultation rates are not consistent for all age/sex groups (table I). The social-class gradient among males of working ages (15-44 and 45-64) is clear, with the highest rates relating to lower social groups. For children and the elderly the pattern is less clear. Among boys there is no simple pattern for the 0-4 year age group but the gradient for the 5-14 group is clearer, and this is the reverse of that observed for working ages. A similar gradient exists for men aged 65-74 but not for the over $75 \mathrm{~s}$.
TABLE II-Family Practitioner Committee areas for which one or more population characteristic weights have an effect of at least $2.5 \% .^{*}$ (England and Wales $=1 \cdot 000$ )

\begin{tabular}{|c|c|c|c|c|c|c|c|}
\hline & Weights: & & $\begin{array}{l}\text { Age } \\
\text { Sex } \\
\text { MS }\end{array}$ & $\begin{array}{l}\text { Age } \\
\text { Sex } \\
\text { MS } \\
\text { HV }\end{array}$ & $\begin{array}{l}\text { Age } \\
\text { Sex } \\
\text { SG }\end{array}$ & $\begin{array}{l}\text { Age } \\
\text { Sex } \\
\text { SG } \\
\text { HV }\end{array}$ & $\begin{array}{l}\text { SG } \\
\mathrm{HV}\end{array}$ \\
\hline \multicolumn{8}{|c|}{ Negative effect } \\
\hline Cleveland ... & .. & . & & 0.973 & & \multirow{3}{*}{0.973} & \multirow{4}{*}{0.973} \\
\hline Hertfordshire & . & . & & & & & \\
\hline $\begin{array}{l}\text { Barnet } \\
\text { Kensington, Chel }\end{array}$ & sea, and $\cdots$ & .. & & & & & \\
\hline Westminster & .. & .. & 0.972 & 0.958 & \multirow{7}{*}{0.971} & \multirow{4}{*}{$\begin{array}{l}0.973 \\
0.965\end{array}$} & \\
\hline Surrey & $\because$ & $\because$ & 0.972 & \multirow{6}{*}{$\begin{array}{l}0.973 \\
0.973 \\
0.972 \\
0.974 \\
0.959\end{array}$} & & & \multirow[t]{6}{*}{0.974} \\
\hline Buckinghamshire & . & . & & & & & \\
\hline $\begin{array}{l}\text { Oxfordshire } \\
\text { Coventry }\end{array}$ & $\therefore$ & $\therefore$ & & & & & \\
\hline Solihull $\quad \ldots$ & $\therefore$ & $\therefore$ & & & & \multirow{3}{*}{0.962} & \\
\hline Walsall & & .. & & & & & \\
\hline St Helens with $\mathrm{K}$ & nowsley.. & 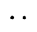 & 0.971 & & & & \\
\hline \multicolumn{8}{|c|}{ Positive effect } \\
\hline Calderdale & .. & . & & & \multirow{7}{*}{1.036} & \multirow{2}{*}{1.029} & \multirow{9}{*}{1.027} \\
\hline City and East Lor & ndon & $\therefore$ & & \multirow{8}{*}{$\begin{array}{l}1.079 \\
1.053 \\
1.055 \\
1.053 \\
1.037 \\
1.040 \\
1.036\end{array}$} & & & \\
\hline East Sussex & . & $\because$. & 1.045 & & & 1.073 & \\
\hline West Sussex & . & $\ldots$ & 1.030 & & & 1.042 & \\
\hline Dorset & .. & $\ldots$ & $1 \cdot 032$ & & & 1.042 & \\
\hline Isle of Wight & & . & 1.030 & & & 1.047 & \\
\hline Cornwall and Isle & $s$ of Scilly & .. & & & & & \\
\hline Devon $\quad .$. & .. $\quad .$. & $\because$ & & & & $1 \cdot 028$ & \\
\hline South Glamorgan & 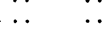 & $\because$ & $1 \cdot 088$ & & 1.085 & 1.036 & \\
\hline
\end{tabular}

*Weight for SG alone had no effect at this level.

Note: the following combinations of population characteristics were allowed for in the various use of weights.

Age: six age bands $-0-4,5-14,15-44,45-64,65-74, \geqslant 75$.

HV = Home visits. Weights home consultations by factor of 2.02 . SG $=$ Social group (see footnote to table I).

(The pattern for females is even less clear.) Thus social-class factors may tend to be partially self-cancelling. Thirdly, at the level of FPCs social structure is remarkably homogeneous, and this dampens the effect of the social-class differences, though below the FPC level much greater variations must exist.

Nevertheless, such weights do have an important effect on a few FPCs, most notably those on the "costa geriatrica." For instance, weighting by age, sex, and marital state and for home visits adds $7.9 \%$ to the population of East Sussex, and similar effects of over $5 \%$ occur in West Sussex, Dorset, and the Isle of Wight. Interestingly, the social-class composition of the population appears surprisingly unimportant, for by itself it produces no weighting outside the range $0.975-1.025$ (England and Wales $=1 \cdot 000$ ). With the reinforcing effect of the home visit allowance, Barnet and Surrey would have their populations reduced by $2 \cdot 7 \%$ and $2 \cdot 6 \%$, respectively, and the City and East London would be the only FPC to have its population increased by more than $2.5 \%$.

TABLE III-Twenty Family Practitioner Committee areas for which Standardised mortality ratio $(S M R)$ weights have the greatest effect (England and Wales $=1 \cdot 000)$

\begin{tabular}{|c|c|c|c|c|c|c|c|c|}
\hline & & \multicolumn{4}{|c|}{ Weights: } & SMR & $\begin{array}{c}\text { SMR } \\
\text { Age } \\
\text { Sex } \\
\text { MS }\end{array}$ & $\begin{array}{l}\text { SMR } \\
\text { Age } \\
\text { Sex } \\
\text { MS } \\
\text { HV }\end{array}$ \\
\hline \multicolumn{9}{|c|}{ Negative effect } \\
\hline West Sussex & .. & $\cdots$ & .. & .. & .. & 0.837 & 0.861 & 0.882 \\
\hline East Sussex & .. & $\because$. & $\because$. & $\because$ & $\because$ & 0.847 & 0.885 & 0.914 \\
\hline Surrey $\ldots$ & $\because$. & $\because$. & $\because$ & $\because$ & $\because$ & & 0.846 & 0.845 \\
\hline Oxfordshire & $\ldots$ & .. & .. & $\because$ & $\because$ & 0.853 & 0.837 & 0.831 \\
\hline Cambridgeshire & & $\ldots$ & . & . & $\because$ & 0.857 & 0.849 & 0.847 \\
\hline Norfolk .. & .. & $\therefore$ & $\therefore$ & . & .. & 0.857 & 0.868 & 0.875 \\
\hline Suffolk .. & .. & $\ldots$ & . & . & $\therefore$ & 0.867 & 0.871 & 0.902 \\
\hline Devon.. & $\because$ & $\because$ & $\because$. & $\because$ & $\because$ & 0.867 & 0.887 & 0.873 \\
\hline Hampshire & $\because$. & $\because$ & $\because$. & $\because$ & $\therefore$ & 0.870 & 0.868 & 0.868 \\
\hline Dorset .. & 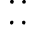 & 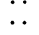 & 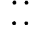 & $\because$ & 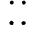 & 0.887 & 0.915 & 0.935 \\
\hline \multicolumn{9}{|c|}{ Positive effect } \\
\hline Manchester & $\ldots$ & .. & . & .. & $\ldots$ & $1 \cdot 167$ & $1 \cdot 147$ & $1 \cdot 147$ \\
\hline & & $\therefore$ & $\because$. & $\because$ & $\therefore$ & $1 \cdot 167$ & $1 \cdot 162$ & 1.159 \\
\hline North Tyneside & & $\therefore$ & $\because$. & $\because$ & $\therefore$ & $1 \cdot 170$ & $1 \cdot 163$ & 1.161 \\
\hline Mid-Glamorgan & & $\because$ & $\because$ & . & $\therefore$ & $1 \cdot 183$ & $1 \cdot 184$ & 1.180 \\
\hline Tameside & & $\therefore$ & $\therefore$ & . & $\therefore$ & $1 \cdot 183$ & $1 \cdot 187$ & 1.184 \\
\hline South Tyneside & & $\because$. & $\because$. & $\because$ & $\because$ & $1 \cdot 187$ & 1.173 & 1.170 \\
\hline Gateshead & .. & $\because$. & $\because$. & $\because$ & $\because$ & 1.200 & $1 \cdot 195$ & 1.189 \\
\hline Wigan.. & $\ldots$ & $\because$. & $\because$. & $\because$ & $\ldots$ & 1.203 & 1.209 & 1.204 \\
\hline Liverpool & $\therefore$ & $\because$ & $\because$ & $\because$ & $\because$ & 1.210 & 1.186 & 1.184 \\
\hline Salford .. & & . & $\ldots$ & .. & . & 1.250 & 1.239 & 1.238 \\
\hline
\end{tabular}

Note: abbreviations are listed and explained in footnotes to tables I and II. 
Variations in use may, however, understate the actual variations in "need" if "need" is measured using the admittedly unsatisfactory indicators for morbidity. ${ }^{8}$ For comparison, therefore, weights using standardised mortality ratios (SMRs) were also calculated: SMRs in the UK, whatever reservations there may be about their relation to morbidity, are at least considered to be largely independent of the supply of health resources. Indeed, this is why they are used in the RAWP formula. The effects of applying SMR-based weightings were, as might be expected, considerable, Using an overall SMR, averaged for the years 1974-6, the weights range from 0.837 to 1.250 (see table III). In other words, at one extreme SMR weighting would reduce the population base by $16.3 \%$, while at the other, it would increase it by $25.0 \%$. The geographical distribution is familiar. The 10 FPCs with heaviest SMR weights are overwhelmingly northern industrial towns; those with the lowest weights are predominantly southern counties.

Nevertheless, the latter group includes some of the FPCs, notably West and East Sussex, whose populations (as noted above) are increased when the weighting is by age. This seems to strengthen the argument that SMRs may be an unreliable guide to demands on services to the extent that (by definition) they exclude the effect of age structure, and that crude death rates may be a more relevant indicator. ${ }^{12}$ Indeed, combining SMRs with the population characteristic weights (table III) has the effect of bringing most of the 20 FPCs closer to the national norm. Only in the case of Oxfordshire are the effects cumulative.

\section{Appropriate population base}

Before looking at the distribution in aggregate, rather than at particular cases, appropriate figures must be found for numbers of patients per general practitioner in each FPC to provide an unweighted baseline against which to compare the weighted distributions. The most frequently cited official figures of list size, such as those recently given in answer to a parliamentary question, ${ }^{13}$ are inappropriate for this analysis for two main reasons.

Firstly, the nominal list-size figures refer to patients appearing on the lists of those general practitioners for whom a particular FPC is responsible whether or not the patient actually lives in the FPC area. This is the familiar RAWP problem of cross-boundary flows of patients. Secondly, the nominal figures are "inflated," since they tend to overstate the numbers of patients actually being served by each general practitioner because of population changes and administration delays in adjusting records.

DHSS calculations for 1976 show that this inflation, when measured by a comparison of registered patients living in an FPC area with OPCS estimates of the resident civilian population in the area,

TABLE IV-Ten Family Practitioner Committee areas with the highest inflation of list sizes (England and $W$ ales $=105$ )

Kensington, Chelsea, and Westminster Camden and Islington Brent and Harrow

... City and East London Lambeth, Southwark, and Lewisham Enfield and Haringey Kingston and Richmond

Liverpool averaged $5 \%$ in England and Wales. More importantly, when analysing the geographical distribution of family practitioners the degree of inflation varies considerably, in one case amounting to almost $30 \%$. Table IV shows the most extreme cases. The ten FPCs with the most inflated lists (between $110 \%$ and $130 \%$ ) are all in conurbations with mobile populations; the top nine are all in the London area. This mobility, of course, may make it particularly difficult to estimate the population base in these areas and doctors' lists may include, for example, some visitors not included in the population figures. Nevertheless, given that, with the single exception of Enfield and Haringey, these nine all have nominal list sizes appreciably lower than the national average, it does seem that nominal list-size figures understate the inequalities in the distribution of general practitioners.

\section{National distribution of general practitioners}

To summarise the findings, table $\mathrm{V}$ shows the impact of these alternative weights on the national distributions of general practitioners as measured by range and variability of the weighted list sizes. For these calculations the population use-weights were applied to figures of population per unrestricted principal general practitioner. Unfortunately, figures for total resident population ${ }^{14}$ had to be used rather than figures for civilian resident population, though the second are used internally by the DHSS for policy purposes. This difference may be expected to have little effect on the distribution shown.

The findings shown in table $\mathrm{V}$ emphasise that actual population figures produce a greater variability in the distribution of list sizes than do nominal figures. The effective minimum list size is 1515 (compared with the nominal 1815); the maximum 2827 (compared with 2769) and the coefficient of variation is $10.5 \%$ (compared with $7 \cdot 7 \%$ ). Adjusting list sizes to allow for inflation and cross-boundary flows of patients has a much greater effect on the apparent distribution of general practitioners than do any of the subsequent weightings for population characteristics. Adjusting for SEG alone has the greatest additional effect, but by comparison brings about a marginal change. Only when SMRs are included do the measures of variability increase considerably further. With SMR alone the minimum list size falls to 1460 , the maximum rises to 3119 , and the coefficient of variation rises to $16.9 \%$. Once again, adding in population characteristics marginally reduces the degree of variation.

\section{Policy implications and conclusions}

The analysis confirms the impression of earlier studies that approached the issue from a rather different perspective ${ }^{3}-$ namely, that the available statistics of nominal list sizes give too favourable a picture of the distribution of general practitioners. When the statistics are adjusted to make allowance for crossboundary flows and inflation the differences between the bestprovided FPCs and the worst-off ones become accentuated. Moreover, although weighting the populations by the characteristics associated with different levels of demand does not greatly alter the national picture, it affects individual FPCs considerably. This might suggest that when NHS planning begins to address itself to the question of the relation between hospital and general-practice resources, at the level of individual area health authorities and FPCs, population characteristics

TABLE V-Impact of alternative weights on summary measures of distribution of general practitioners in England and Wales

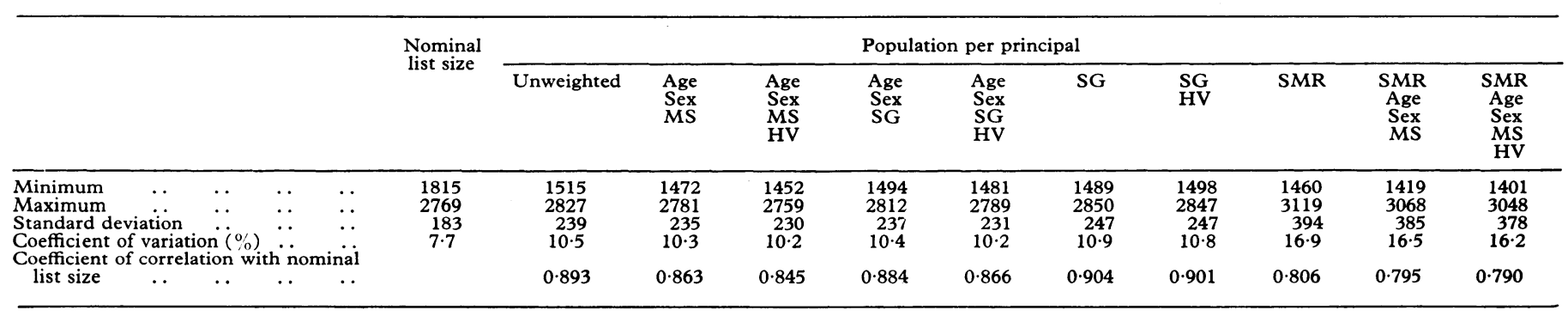

Note: abbreviations are listed and explained in footnotes to tables I and II. 
such as age and socioeconomic structure must be taken into account.

Our analysis also emphasises the complexity of any such exercise. For example, in terms of crude numbers, eight of the London FPCs seem to be rather favourably placed when their nominal below-average list sizes are further corrected to allow for their above-average rate of list inflation. Specifically in the City and East London area the social structure clearly generates extra demands-most importantly a particularly heavy burden of home visits. Here at least the inflation may be an example of fortuitous compensation, though this begs questions about the quality, as distinct from the quantity, of the general-practitioner service available. Additionally, and more fundamentally, the statistics of use may understate the needs of manual workers as reflected in the (admittedly unsatisfactory) indicators of morbidity that are available. The SMR-based weights-if we assume that mortality has at least some relationship to morbidity - seem to suggest that using indicators of morbidity, rather than of use, might show further imbalances in the distribution of general practitioners.

Overall, the results of our analysis underline the need to develop more-sensitive measures of the population and its likely demand for services in order to formulate and monitor policy about the distribution of general practitioners. In addition to developing indicators of morbidity that are sensitive to "need" for primary care and available at the level of individual FPCs, policy should be based on better information about population characteristics as well as practice characteristics-for example, account may need to be taken of the number of supporting staff available to general practitioners in different FPCs. The muchneeded debate about the relation of the distribution of generalpractitioner services to that of the rest of the Health Service is too important to be based on conclusions drawn from unadjusted and unweighted "nominal" list sizes.
We thank Mrs Pauline Rogers, MSc, for her invaluable help in the data preparation and computer analysis. We would also like to acknowledge the help of the DHSS and OPCS in providing us with unpublished data, though responsibility for its analysis and interpretation lies entirely with us.

\section{References}

${ }^{1}$ DHSS, Sharing Resources for Health in England: Report of the Resource Allocation Working Party. London HMSO, 1976.

2 Butler, J R, Family Doctors and Public Policy. London, Routledge and Kegan Paul, 1973.

${ }^{3}$ Butler, J R, and Knight, R, Health Trends, 1976, 8, 8.

${ }_{4}$ Williams, A, in Economic Policies and Social Goals, ed A J Culyer, chap 4 p60. London, Martin Robertson, 1974

${ }^{5}$ Buxton, M J, and Klein, R E, Allocating Health Resources: A Commentary on the Report of the Resource Allocation Working Party, Royal Commission on the NHS: Research Paper No 3. London HMSO, 1978.

${ }^{6}$ Buxton, M J, The Application of Population Use-Weights to Measures of GP List Size, Policy Studies Institute Working Paper. London, PSI, 1979.

7 Morrell, D C, Gage, H G, and Robinson, N A, fournal of the Royal College of General Practitioners, 1970, 19, 331.

${ }^{8}$ Forster, D P, Health Trends, 1976, 8, 29.

9 Office of Population Censuses and Surveys (Social Survey Division), The General Household Survey 1976. London, HMSO, 1978.

10 Office of Population Censuses and Surveys, Morbidity Statistics from General Practice: Second National Study 1970-1971, Studies on Medical and Population Subjects No 26. London, HMSO, 1974.

${ }^{11}$ Buchan, I C, and Richardson, I M, Time Study of Consultations in General Practice, Scottish Health Service Studies No 27. Edinburgh, Scottish Home and Health Department, 1973.

${ }^{12}$ Barr, A, and Logan, R F L, Lancet, 1977, 1, 994.

${ }^{13}$ British Medical fournal, 1978, 2, 213.

14 Office of Population Censuses and Surveys, Mid-1976 Population Estimates, OPCS Monitor PP1 77/2. London, OPCS, 1977.

(Accepted 11 December 1978)
WORDS It is a pity that medical dictionaries omit the derivations of drug names, because the exploration of this field is quite fascinating, although too large for a detailed account in these short notes. Fortunately the pharmaceutical names of most drugs are based on terms in organic chemistry. Here are the derivations of a few common building-blocks from which terms in organic chemistry are constructed.

-ol Suffix denoting an alcohol. Alcohol is derived from the Arabic al kohl, from the similar Hebrew, meaning cosmetic eye-shadow made from finely powdered antimony sulphide obtained by sublimation. Later, it was applied to any substance obtained by sublimation or distillation including alcohol of wine. Eventually restricted to this substance, the words "of wine" were dropped.

METHYL G methy, wine +hyle, wood; wood spirit.

ETHYL $G$ aither, the clean upper air. Originally adopted for diethyl ether (anaesthetic ether) because it was volatile and cleansmelling.

PROPYL G pro, before + pion, fat. So called because it is the first of a series of acids whose derivatives are oily (the fatty acids).

BUTYL G boutyron, butter. Butyric acid is formed in rancid butter.

AMYL L amylum, starch. Its alcohol was first obtained from fusel (Ger rotten, bad) oil separated in rectifying (purifying) alcoholic spirits distilled from fermented grain or potatoes.

ACET- L acetum, vinegar that contains about $6 \%$ of acetic acid. Note in passing that ACETABULUM is a little vinegar cup.

CITR- L citrus, lemon, the juice of which contains about $6 \%$ of citric acid.

FORM- L formica, ant. Formic acid is present in ant stings. It was so named by John Ray (1670), who obtained it by distillation of red ants.

LACT- L lac, lactis, milk. Lactic acid is formed in sour milk.

OXAL- Oxalic acid was so called because it was first prepared from oxalis, the wood sorrel. This in turn was so named because of the sharp, acidic taste (G oxys, sharp, acid) of the leaves.

CYAN- G kyanos, dark blue-from the blue colour of ferric ferrocyanide, also known as Prussian blue after its discoverer Diesbach, an eighteenth-century artist and colour maker in Berlin. Incidentally, also, the blue of the original blue prints for making copies of plans. ALDEHYDE al(cohol) + dehyd(rogenatum). Because it is made by oxidation of an alcohol.

PHEN G phaino, to appear, shine. Phenolic and other coal-tar substances were byproducts of the manufacture of gas from coal for illuminating purposes.

BENZ Arab luban-jawi, frankincense of Java, the fragrant resin obtained from a Javanese tree. Luban-jawi gave lo-benjuy, from which the lo was dropped in the mistaken belief that it was an article thereafter benjoin and benzoin, which contains benzoic acid esters.

ESTER Contracted by Gmelin from Ger es(sigä)ther, acetic ether, to distinguish it from ordinary ethers, since it was a compound of an alcohol and an acid radical.

Azo Denotes the presence of nitrogen ( $\mathrm{F}$ azote) in a compound. Azote was so called because it did not support life, G $a$, not $+z \bar{o} o s$, life.

THIO G theion, sulphur.

$\mathrm{AM}$ (-INE -IDE) Ammonia was the name given by Bergman in 1782 to the gas obtained from sal ammoniac. Sal ammoniac, or salt of Ammon, was obtained from the dung of camels near the temple of Jupiter Ammon (the Egyptian god Amun) in Libya.

\section{Correction}

\section{Blindness and partial sight}

This article by Mr P A Gardiner (20 January, p 180) stated that the benefits of registration as a blind person included a small pension. Blind people do not qualify for a pension as such but they are entitled to an extra tax allowance and a higher rate of supplementary benefit.

\section{How to do it: Choose and use a calculator}

In this article by Dr T D V Swinscow (3 February, p 326) the symbol $\sqrt{\mathrm{x}}$ was misprinted as $\sqrt{\mathbf{x}}$. 